\title{
The Dark Triad of personality and momentary affective states: an experience sampling study
}

\author{
Irena Pilch (D) ${ }^{1 \cdot A, B, C, D, E, F}$, Neal Lathia (D) ${ }^{2 \cdot B, E}$, Krzysztof Wiesebach ${ }^{1 \cdot B, F}$ \\ 1: University of Silesia, Katowice, Poland \\ 2: University College London, London, United Kingdom
}

BACKGROUND

The Dark Triad (DT; Machiavellianism, narcissism, psychopathy) refers to three distinct but interrelated socially undesirable traits which are associated with an antagonistic and exploitative strategy of conduct. The aim of the current study was to investigate the relationships between the DT traits and momentary affective states using a longitudinal approach.

PARTICIPANTS AND PROCEDURE

University students $(N=81)$ completed personality measures and participated in an 8-day experience-sampling study. Subjects provided $n=2572$ responses. Multilevel analyses were used to assess relationships between the DT and affect.

\section{RESULTS}

All the DT traits were associated with negative affect: the two psychopathy dimensions (boldness and meanness) negatively, and the remaining traits positively. Boldness and grandiose narcissism were associated with positive affect. The presence of others differentiated the relationships between Machiavellianism and meanness and negative affective states.

CONCLUSIONS

The findings showed a tendency to experience more negative affect in everyday life in people with higher levels of grandiose and vulnerable narcissism, Machiavellianism, and disinhibition.

\section{KEY WORDS}

Machiavellianism; psychopathy; grandiose narcissism; vulnerable narcissism; momentary affect

Corresponding author - Irena Pilch, Ph.D., University of Silesia, 53 Grażyńskiego Str., 40-126 Katowice, Poland, e-mail: irena.pilch@us.edu.pl

Authors' Contribution - A: Study design · B: Data collection · C: Statistical analysis · D: Data interpretation ·

E: Manuscript preparation · F: Literature search · G: Funds collection

to Cite this ARTICLE - Pilch, I., Lathia, N., \& Wiesebach, K. (2020). The Dark Triad of personality and momentary

affective states: an experience sampling study. Current Issues in Personality Psychology, 8(1), 10-17.

RECEIVED 15.02.2019 • REVIEWED 27.11.2019 • ACCEPTED 05.03.2020 • PUBLISHED 31.03.2020 


\section{BACKGROUND}

The Dark Triad (DT) refers to three distinct (but interrelated) socially undesirable personality traits: Machiavellianism (i.e., manipulativeness, interpersonal coldness, cynicism, and deception for self-benefit), subclinical narcissism (i.e., grandiosity, vanity, and self-centeredness) and subclinical psychopathy (e.g., emotional deficits, impulsiveness, and aggressiveness; Paulhus \& Williams, 2002; Pilch, 2014). These traits have been associated with antagonistic and exploitative social behaviors and with low agreeableness and honesty-humility (Jonason \& Webster, 2012). In particular, callousness and empathy deficits, which may facilitate the exploitation of others, seem to be common elements of "dark" personalities (e.g., Jonason \& Krause, 2013). On the other hand, the differences between the particular "dark" traits (and their dimensions) may be visible, inter alia, in the domain of emotionality.

The objective of the current study was to examine the relationships between the DT traits and momentary affect (MA), using experience sampling methodology (ESM). To the best of our knowledge, no study to date has used the ESM to measure daily affect in association with all of the DT traits considered together. We also applied a dimensional approach to investigating the DT, because in cross-sectional research the types of narcissism and the dimensions of psychopathy have shown opposing relationships with emotionality. Such an approach can be used for identifying differences in MA among the constructs. These differences, in turn, can be interpreted in the context of well-being of individuals with "dark" personalities.

The vast majority of studies on associations between the particular DT traits and emotionality have used correlational designs and self-report questionnaires to investigate cross-sectional relationships. According to the results of these studies, grandiose type of narcissism (GN; connected with higher selfesteem, overt grandiosity and dominance) was associated with positive affect (e.g., Żemojtel-Piotrowska, Clinton, \& Piotrowski, 2014). Vulnerable type of narcissism (VN; associated with lower self-esteem, covert grandiosity and approval seeking) correlated with negative affect and inversely with positive affect (e.g., Miller et al., 2011). Machiavellianism was associated with emotional instability and susceptibility to stress (e.g., Jakobwitz \& Egan, 2006). In turn, the relationship between psychopathy and emotionality depends on the conceptualization of psychopathy (Skeem, Poythress, Edens, Lilienfeld, \& Cale, 2003). Psychopathy measured as unitary construct correlated with negative affect and negatively with positive affect (e.g., Love \& Holder, 2014). When primary and secondary psychopathy were distinguished, the primary variant of psychopathy was associated with positive affect and inversely with negative affect, and secondary psychopathy correlated only with negative affect (e.g., Del Gaizo \& Falkenbach, 2008).

The most recent attempt to deal with the problem of multidimensionality is the triarchic conceptualization of psychopathy, proposing three distinct phenotypic dispositions (Patrick, Fowles, \& Krueger, 2009): disinhibition (i.e., impulsiveness, hostility, irresponsibility, and reactive aggression), meanness (i.e., predatory exploitativeness, arrogance, destructiveness, and cruelty), and boldness (fearlessness, dominance, assertiveness, and venturesomeness). Recently, the triarchic model of psychopathy has been used in many studies on clinical and nonclinical samples. This model is useful for investigating psychopathy within the DT, because it contains boldness, which is considered as a relatively adaptive element of psychopathy (e.g., Sleep, Weiss, Lynam, \& Miller, 2019). Research showed significant relationships between the triarchic psychopathy dimensions and affect (measured as a trait-like feature). Negative affect correlated positively with disinhibition and negatively with boldness, whereas positive affect correlated positively with boldness and negatively with disinhibition (Brislin, Drislane, Smith, Edens, \& Patrick, 2015).

This study aimed at investigating relationships between the DT traits (i.e., Machiavellianism, narcissism, and psychopathy) and MA. The two types of narcissism (GN and $\mathrm{VN}$ ) and three dimensions of psychopathy (disinhibition, meanness, and boldness) were analyzed. The first research question concerned the univariate relationships between the particular DT traits, positive momentary affect (PMA), and negative momentary affect (NMA) in two types of situations (when a person is alone or in the presence of others). For individuals with "dark" personalities, who tend to deceive and manipulate others for personal gain, the presence (or absence) of other people may be important and may differentiate the relationships between levels of "dark" traits and MA (see Fatfouta, 2017). However, we did not formulate the predictions regarding these potential differences because of the exploratory character of this part of our study. Taking into account both the results of past studies and the features of the constructs, we formulated the hypotheses detailed below. NMA would be negatively related to GN (H1a) and boldness (H1b) and positively related to $\mathrm{VN}(\mathrm{H} 2 \mathrm{a})$, Machiavellianism (H2b), and disinhibition (H2c). In turn, PMA would be positively related to $\mathrm{GN}(\mathrm{H} 3 \mathrm{a})$ and boldness $(\mathrm{H} 3 \mathrm{~b})$ and negatively related to $\mathrm{VN}(\mathrm{H} 4 \mathrm{a})$ and disinhibition (H4b). The second research question concerned the unique relationships of each "dark" trait with PMA/ NMA while controlling for the variables for which associations with affect are well-established. In the current study the perceived stressfulness of the situation (treated as a situational variable), as well as two 
general personality traits - Emotionality and Extraversion (dispositional variables) - were analyzed (see Uziel, 2006).

\section{PARTICIPANTS AND PROCEDURE}

\section{PARTICIPANTS}

The study used experience sampling, which allowed us to collect information about participants' affective states measured via self-report in real time and in natural settings. Eighty-one university students (20 males, age $M=22.00, S D=2.70$ ) were recruited from a large university in Poland. Participation in the current study was voluntary, anonymous and without compensation.

\section{PROCEDURE}

During the initial session, the participants completed several paper-and-pencil questionnaires, including measures of Machiavellianism, narcissism, psychopathy, and general personality traits. Two weeks later they downloaded a smartphone application (Easy-M) from the Google Play Store. This application was designed to conduct smartphone-based experiencesampling studies and it was previously used in other published studies (e.g., Galante et al., 2018). The app had been configured to send six notifications a day at approx. two-hour intervals for eight consecutive days. After each signal, subjects were asked to stop activities and complete an online survey (i.e., answer several questions using their mobile devices). Participants evaluated their current emotional states and stressfulness of the current situation. They responded, on average, to 31 notifications $(S D=4$, range 7-35), which gave 2572 survey responses.

\section{MEASURES}

Momentary affective states were assessed with six adjectives: positive affect words i.e. "cheerful" (wesoły), "content” (zadowolony), "enthusiastic" (entuzjastyczny), and negative affect words i.e. "angry" (rozzłoszczony), "depressed” (przygnębiony), "anxious" (zaniepokojony). These adjectives were chosen using Russell's circumplex model of affect (Russell, 1980). The participants described their current emotions (e.g., "I feel cheerful right now") using a 7-point scale from 1 (not at all) to 7 (extremely). An exploratory factor analysis identified two factors ("PMA" and "NMA") that explained $76 \%$ of the MA variance. The scores on the items "cheerful", "content" and "enthusiastic" were averaged to form a PMA index (Cronbach's $\alpha=.92$ ), whereas the average of ratings on "angry", "depressed", and "nervous" formed an NMA index $(\alpha=.82)$. PMA and NMA were used in the analyses as indicators of MA. Stressfulness was measured with the question "How stressful is your current situation for you?" (1 - not at all, 7 - extreme$l y)$. Additionally, the participants answered the question "Are you alone or with others?".

Dark Triad. A Polish version of the Mach IV (Christie \& Geis, 1970) was used to assess Machiavellianism (20 items; 1 - fully disagree, 7 - fully agree; $\alpha=.78$ ). A Polish validated adaptation of the Narcissistic Personality Inventory (NPI; Bazińska \& DratRuszczak, 2000) assessed GN (34 items; 1 - it's not me, 5 - it's $m e ; \alpha=.93$ ). A Polish translation of the Hypersensitive Narcissism Scale (HSNS; Hendin \& Cheek, 1997) assessed VN (10 items; 1 - strongly disagree, 5 - strongly agree; $\alpha=.69)$. Triarchic psychopathy was assessed with the TriPM-41 (41 items; 0 - false, 3 -true; boldness 15 items, $\alpha=.83$; meanness 10 items, $\alpha=.86$; disinhibition 16 items, $\alpha=.73$ ), a shortened Polish validated version of the Triarchic Psychopathy Measure (Pilch, Sanecka, Hyla, \& Atłas, 2015). Items were averaged for each scale and subscale to create indexes. The Polish translated 60 -item version of the HEXACO-PI-R (Ashton \& Lee, 2009) was used to assess general personality traits $(1-$ strongly disagree, 5 - strongly agree). Items were averaged for each domain. The scores on Extraversion $(\alpha=.83)$ and Emotionality $(\alpha=.90)$ were used in analyses.

\section{STATISTICAL ANALYSES}

The data from the ESM have a multilevel structure and were analyzed using multilevel random coefficient models (MRCM; Nezlek, 2007). Simulation studies showed that a sufficient sample size at level 2 of the analysis is slightly larger than 50 units (in the current study - participants) and sample size between 50 and 100 participants leads to unbiased estimates of the regression coefficients and standard errors (Maas \& Hox, 2005). This indicates that the sample size in our study was large enough to achieve unbiased regression coefficients. We used the HLM-7 program and the restricted maximum likelihood method of estimation. In the analyses the measurements of MA (treated as level-1 data) were nested within participants and the DT traits were treated as level-2 data. The predictors were standardized before the analyses. Meanness was log-transformed to provide a normal distribution. Fixed effects with robust standard errors were estimated. The coefficients were modelled as random.

The associations between the DT traits and MA were analyzed separately in two types of situations: (a) a participant was alone (1163 measurements) or (b) a participant was with other people (1409 measurements) while answering survey ques- 
tions. Three types of multilevel models were tested with PMA and NMA as outcome variables. Models A had only one level-2 predictor (the DT trait). These models provided information on bivariate relationships between MA and the DT traits. Models B had two predictors: stressfulness (level 1) and the DT trait (level 2). In turn, Models $C$ had four predictors: stressfulness (level 1) and the DT trait, Emotionality, and Extraversion (level 2). These models made it possible to establish whether the relationships between the DT traits and MA remained significant after controlling for important situational (stressfulness) and dispositional (Emotionality and Extraversion) predictors of affect.

\section{RESULTS AND DISCUSSION}

Table 1 presents descriptive statistics and correlations between the variables for the sample. The correlations with MA were computed on the basis of the means per person across all responses. (Descriptive statistics for situations: when participants were alone - PA: $M=3.99, S D=1.60$, NA: $M=2.25, S D=1.40$, stressfulness: $M=2.35, S D=1.80$; when participants were with other people - PA: $M=4.51, S D=1.60$, NA: $M=2.11, S D=1.30$, stressfulness $M=2.23, S D=1.70$ ). To check whether there was a substantial amount of within-person variability in momentary affect, a series of unconditional random intercept models was estimated to predict PMA and NMA (within-person: $\mathrm{y}_{\mathrm{ij}}=\beta_{0 \mathrm{j}}+\mathrm{r}_{\mathrm{ij}}$, between-person: $\beta_{0 \mathrm{j}}=\gamma_{00}+\mathrm{u}_{0 \mathrm{j}}$. These models have no predictors; however, they produce estimates for variance components at level 1 (i.e., measurements; $\sigma^{2}$ ) and level 2 (i.e., participants; $\tau$ ) of the analysis, which were used to examine how much of the total variance of momentary affect can be accounted for by observations and participants. For PMA $\left(\sigma^{2}=1.98, \tau=0.66\right.$, ICC $\left.=0.25\right)$ and NMA $\left(\sigma^{2}=1.17, \tau=0.6\right.$, ICC $\left.=0.34\right)$ a substantial part of their variance was at the within-person level.

A series of multilevel analyses was performed to assess the relationships between each DT trait and PMA/NMA in two types of situation (alone/not alone). In Models $A$, there were no predictors at level 1 of the model (within-person: $\mathrm{y}_{\mathrm{ij}}=\beta_{\mathrm{ij}}+\mathrm{r}_{\mathrm{ij}}$ ), so this model estimated within-person means for each rating of momentary affect. Level 2 of the model examined associations between individual differences in ratings of MA and the DT trait (between-person: $\beta_{0 \mathrm{j}}=\gamma_{00}+\gamma_{01}$ (Trait) $+\mathrm{u}_{0 \mathrm{j}}$ ). In Models B, a level 1 predictor (stressfulness) was added (within-person: $y_{i j}=\beta_{0 j}+\beta_{i j}\left(\right.$ STRESS) $+r_{i j}$, between-person: $\beta_{0 \mathrm{j}}=\gamma_{00}+\gamma_{01}$ (Trait) $+\mathrm{u}_{0 \mathrm{j}}, \beta_{1 \mathrm{j}}=\gamma_{10}+\mathrm{u}_{1 \mathrm{j}}$. In Models $\mathrm{C}$, two additional level 2 predictors were introduced (within-person: $\mathrm{y}_{\mathrm{ij}}=\beta_{0 \mathrm{j}}+\beta_{\mathrm{ij}}$ (STRESS) $+\mathrm{r}_{\mathrm{ij}}$, between-person: $\beta_{0 \mathrm{j}}=\gamma_{00}+\gamma_{01}$ (Trait) $+\gamma_{02}$ (Emotionality) $+\gamma_{03}$ (Extraversion) $+u_{0 j}, \beta_{1 j}=\gamma_{10}+u_{1 j}$. The results of the analyses are presented in Table 2.

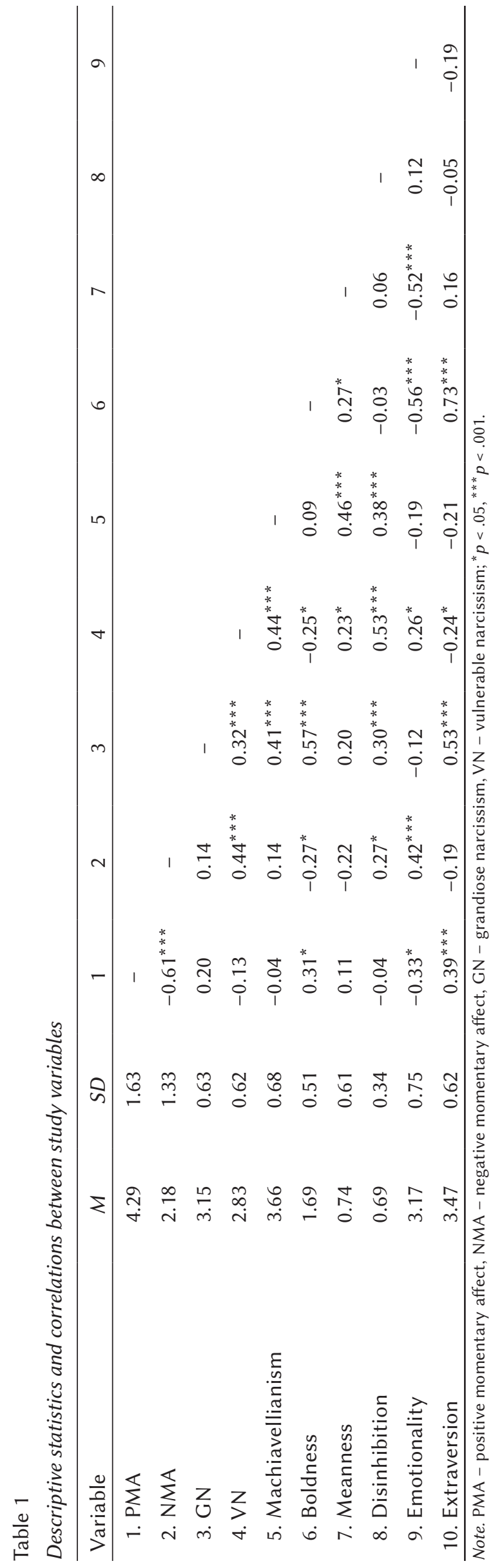




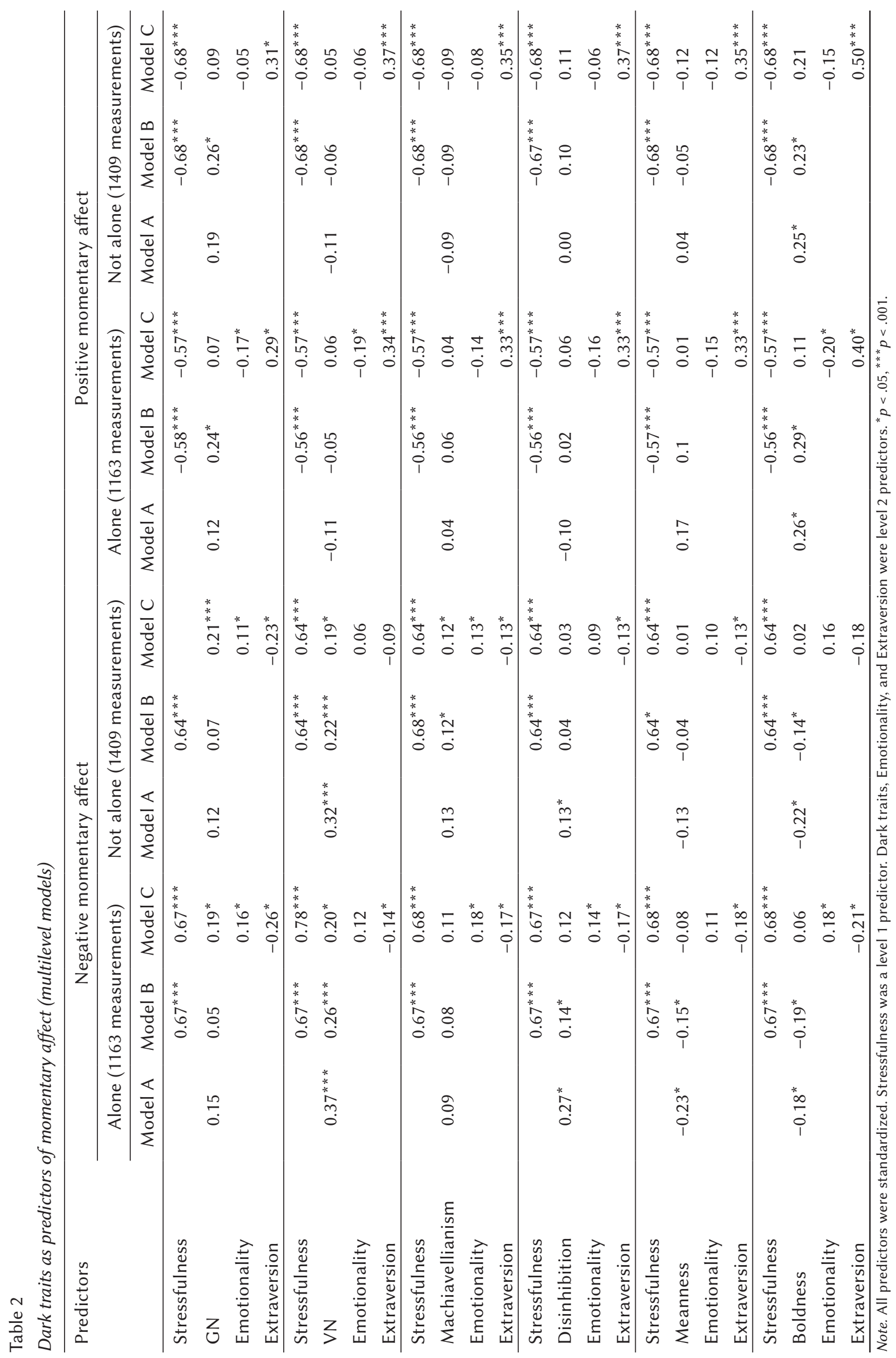


The results indicate that the DT traits differ in their associations with NMA. Contrary to expectations, when GN was considered separately (H1a, Models A) or with stressfulness (Models B), there was no significant relationship between GN and NMA in both types of situation (alone/not alone). However, GN became a significant positive predictor of NMA when Extraversion and Emotionality were controlled (Models C). This result suggests the existence of a suppressing effect of Extraversion and Emotionality on the relationship between GN and NMA. The shared variance in the predictors was removed when GN, Extraversion, and Emotionality were entered into the regression together. When this overlapping variance was statistically controlled, the strength of the relationship GN-NMA increased. This result is not consistent with the idea (which received support in cross-sectional studies) that one of the main differences between GN and VN is that these types of narcissism tend to show opposite relationships with NA (Miller et al., 2011).

As expected, boldness was a negative predictor of NMA (H1b, Models A) in both types of situation (alone/not alone), and it remained significant when stressfulness was taken into account (Models B). However, this relationship disappeared when Extraversion and Emotionality were included in the model (Models C). Thus, boldness had no unique relationship with NMA. It may suggest that boldness predicted NMA because of the variance shared with Extraversion and Emotionality. After statistically removing variance associated with these general personality traits, the relationship between boldness and NMA lost significance. The above differences between GN and boldness in their relations to NMA can enable differentiation between these two constructs, which have been highly correlated in previous studies.

As predicted, VN was positively associated with NMA (H2a, Models A) in both types of situation (alone/not alone). This result was consistent across all the models: VN had a unique relationship with NMA even after controlling for potential overlap with stressfulness, Emotionality and Extraversion. However, this association became weaker when the control variables were added (Models B and C). These results are consistent with previous studies which have investigated NA as a trait-like variable (e.g., Miller et al., 2011).

Machiavellianism was weakly (positively) related to NMA (H2b) only in situations where participants were not alone and this relationship became significant after controlling for stressfulness (Models B and C), which only partially supports our hypothesis. On the other hand, this result encourages further studies on the specificity of emotional experiences of Machiavellian individuals. Machiavellian negative views of human nature can be responsible for a propensity to experience negative emotions only in the presence of "dangerous others". In turn, disinhibition showed a bivariate (positive) association with NMA (Models A, $\mathrm{H} 2 \mathrm{c}$ ), which supported our prediction, and this relationship was stronger in situations when participants were alone. In both types of situation, the association between disinhibition and NMA turned out to be non-significant after controlling for control variables (Models B and C).

The bivariate associations between meanness and NMA were negative and they reached significance only in situations where participants were alone (Models A and B). As in the case of boldness, the relationship between meanness and NMA lost significance when Extraversion and Emotionality were controlled (Model C, alone). Both boldness and meanness are formed on the ground of fearless temperament (Patrick et al., 2009). This common feature of both psychopathy domains can be manifested in lower NMA. However, the participants with higher meanness (but not with higher boldness) reported less negative affective states only when they were alone. This difference between boldness and meanness may concern only certain types of emotional states (e.g., anger), which should be explored in future studies. The strength of associations between the DT traits and NMA was calculated for both social and nonsocial contexts. The effects of VN and boldness on NMA seemed to be rather insensitive to the context (i.e., the presence or absence of others), but in the case of meanness (and, to some degree, disinhibition) these relationships were visible mainly in situations when participants were alone. Further investigations will be necessary for a better understanding of this finding. In turn, Machiavellianism was weakly connected with NMA only when the participants were with others. People higher in Machiavellianism share highly pessimistic, cynical views of the social world and other people, and they can feel compelled to defend their interests against others. Moreover, a Machiavellian strategy can be associated with the risk of being caught and sanctioned and fear of retaliation. These factors may be the sources of negative affective states in everyday life in Machiavellian individuals.

The positive association between GN and PMA (H3a) was significant in both types of situation (alone/not alone), but only when stressfulness was controlled (Models B). This result is partly consistent with findings of past studies, where GN correlated positively with PA (e.g., Żemojtel-Piotrowska et al., 2014). In turn, the expected positive relationship between boldness and PMA (H3b) was fully confirmed by the data (Models A, B) in both types of situation (alone/not alone). Both these relationships lost significance after controlling for Extraversion and Emotionality (Models C). Thus, GN and boldness did not predict PMA when the variance shared with Extraversion and Emotionality was statistically controlled. This finding is consistent with past research in which 
GN and boldness were related to Extraversion and Emotionality/Neuroticism (Miller et al., 2011). On the other hand, we did not find situational differences in the association between GN and PMA, despite the fact that some narcissistic needs can be satisfied effectively only in the presence of others. Contrary to the expectations, VN (H4a) and disinhibition (H4b) were not associated with PMA. Similarly, Machiavellianism and meanness were not significant predictors of PMA.

\section{CONCLUSIONS, LIMITATIONS AND FUTURE DIRECTIONS}

In the current study we used the ESM, which enables measurement of momentary experiences and emotions during a chosen period of time within natural situations. According to the results of multilevel analysis, the DT traits showed more associations with NMA than with PMA. Boldness and GN were the only "dark" traits which were associated with PMA in this study. Only boldness showed a pattern of relationships with MA which is considered beneficial for an individual: positive with PMA and negative with NMA. In general, the observed patterns of relationships support the majority of our hypotheses regarding connections between the DT traits and NMA. Two groups of traits showing opposing patterns of relationships with NMA (positive for VN and disinhibition, negative for meanness and boldness) can be distinguished. The association between NMA and VN was the strongest one. Moreover, vulnerable narcissism was the "dark" trait which had unique associations with NMA (after controlling for Emotionality and Extraversion). From the evolutionary point of view, the DT can be treated as a basis for a "cheater strategy", which is connected with some evolutionary and personal advantages (e.g., more sex partners or profits obtained at the expense of others in everyday life; Jonason, Li, \& Buss, 2010). However, this strategy also bears some costs for individuals with "dark" personalities, which may be visible in the sphere of emotionality. $\mathrm{VN}$ seems to be a trait with negative consequences for an individual in the area of emotional life and the opposite is true for boldness.

We found some evidence that the presence (or absence) of others can differentiate the relationships between levels of "dark" traits and NMA. In our sample Machiavellianism predicted NMA only in situations where the participants were with others and meanness predicted NMA only when they were alone. However, further research is needed to confirm these findings in larger and more diverse samples. The Dark Triad was measured via self-report questionnaires. Self-reports are commonly used to measure personality traits; however, caution is needed when assessing psychopathic traits (see Groth \& Kleka, 2018). Thus, future studies should use self-reports conjointly with other measures.

\section{References}

Ashton, M. C., \& Lee, K. (2009). The HEXACO-60: a short measure of the major dimensions of personality. Journal of Personality Assessment, 91, 340345. https://doi.org/10.1080/00223890902935878

Bazińska, R., \& Drat-Ruszczak, K. (2000). Struktura narcyzmu w polskiej adaptacji kwestionariusza NPI Ruskina i Halla [The structure of narcissism in the Polish adaptation of Ruskin's and Hall's NPI questionnaire]. Czasopismo Psychologiczne, 6, 171-188.

Brislin, S. J., Drislane, L. E., Smith, S. T., Edens, J. F., \& Patrick, C. J. (2015). Development and validation of triarchic psychopathy scales from the Multidimensional Personality Questionnaire. Psychological Assessment, 27, 838-851. https://doi.org/10.1037/ pas0000087

Christie, R., \& Geis, F. (1970). Studies in Machiavellianism. New York: Academic Press.

Del Gaizo, A. L., \& Falkenbach, D. M. (2008). Primary and secondary psychopathic-traits and their relationship to perception and experience of emotion. Personality and Individual Differences, 45, 206-212. https://doi.org/10.1016/j.paid.2008.03.019

Fatfouta, R. (2017). To be alone or not to be alone? Facets of narcissism and preference for solitude. Personality and Individual Differences, 114, 1-4. https://doi.org/10.1016/j.paid.2017.03.047

Galante, J., Dufour, G., Vainre, M., Wagner, A. P., Stochl, J., Benton, A., Lathia, N., Howarth, E., \& Jones, P. B. (2018). A mindfulness-based intervention to increase resilience to stress in university students (the Mindful Student Study): a pragmatic randomised controlled trial. The Lancet Public Health, 3, e72-e81. https://doi.org/10.1016/ S2468-2667(17)30231-1

Groth, J., \& Kleka, P. (2018). Patterns of intentional faking in questionnaire-based study of psychopathy. Current Issues in Personality Psychology, 6, 305-317. https://doi.org/10.5114/cipp.2018.80199

Hendin, H. M., \& Cheek, J. M. (1997). Assessing hypersensitive narcissism: a reexamination of Murray's narcissism scale. Journal of Research in Personality, 31, 588-599. https://doi.org/10.1006/ jrpe.1997.2204

Jakobwitz, S., \& Egan, V. (2006). The dark triad and normal personality traits. Personality and Individual Differences, 40, 331-339. https://doi.org/10.1016/j. paid.2005.07.006

Jonason, P. K., \& Krause, L. (2013). The emotional deficits associated with the Dark Triad traits: Cognitive empathy, affective empathy, and alexithymia. 
Personality and Individual Differences, 55, 532-537. https://doi.org/10.1016/j.paid.2013.04.027

Jonason, P. K., Li, N. P., \& Buss, D. M. (2010). The costs and benefits of the Dark Triad: Implications for mate poaching and mate retention tactics. Personality and Individual Differences, 48, 373-378. https://doi.org/10.1016/j.paid.2009.11.003

Jonason, P. K., \& Webster, G. D. (2012). A protean approach to social influence: Dark Triad personalities and social influence tactics. Personality and Individual Differences, 52, 521-526. https://doi. org/10.1016/j.paid.2011.11.023

Love, A. B., \& Holder, M. D. (2014). Psychopathy and subjective well-being. Personality and Individual Differences, 66, 112-117. https://doi.org/10.1016/j. paid.2014.03.033

Maas, C. J., \& Hox, J. J. (2005). Sufficient sample sizes for multilevel modeling. Methodology, 1, 86-92. https://doi.org/10.1027/1614-2241.1.3.86

Miller, J. D., Hoffman, B. J., Gaughan, E. T., Gentile, B., Maples, J., \& Campbell, K. W. (2011). Grandiose and vulnerable narcissism: a nomological network analysis. Journal of Personality, 79, 1013-1042. https://doi.org/10.1111/j.1467-6494.2010.00711.x

Nezlek, J. B. (2007). A multilevel framework for understanding relationships among traits, states, situations and behaviours. European Journal of Personality, 21, 789-810. https://doi.org/10.1002/per.640

Patrick, C. J., Fowles, D. C., \& Krueger, R. F. (2009). Triarchic conceptualization of psychopathy: Developmental origins of disinhibition, boldness, and meanness. Development and Psychopathology, 21, 913-938. https://doi.org/10.1017/S0954579409000492

Paulhus, D. L., \& Williams, K. M. (2002). The dark triad of personality: Narcissism, Machiavellianism, and psychopathy. Journal of Research in Personality, 36, 556-563. https://doi.org/10.1016/S00926566(02)00505-6

Pilch, I. (2014). Makiawelizm, narcyzm, psychopatia: ciemna triada jako próba opisania osobowości eksploatatora [Machiavellianism, narcissism, psychopathy: the dark triad as an attempt at describing the personality of an exploiter]. Chowanna, 43, 165-181.

Pilch, I., Sanecka, E., Hyla, M., \& Atłas, K. (2015). Polska adaptacja skali TriPM do badania psychopatii w ujęciu triarchicznym [The Polish adaptation of the TriPM scale measuring psychopathy]. Psychologia Społeczna, 10, 435-454. https://doi.org/10. 7366/1896180020153506

Russell, J. A. (1980). A circumplex model of affect. Journal of Personality and Social Psychology, 39, 1161-1178. https://doi.org/10.1037/h0077714

Skeem, J. L., Poythress, N., Edens, J. F., Lilienfeld, S. O., \& Cale, E. M. (2003). Psychopathic personality or personalities? Exploring potential variants of psychopathy and their implications for risk assessment. Aggression and Violent Behavior, 8, 513-546. https://doi.org/10.1016/S1359-1789(02)00098-8
Sleep, C. E., Weiss, B., Lynam, D. R., \& Miller, J. D. (2019). An examination of the Triarchic Model of psychopathy's nomological network: a meta-analytic review. Clinical Psychology Review, 71, 1-26. https://doi.org/10.1016/j.cpr.2019.04.005

Uziel, L. (2006). The extraverted and the neurotic glasses are of different colors. Personality and Individual Differences, 41, 745-754. https://doi. org/10.1016/j.paid.2006.03.011

Żemojtel-Piotrowska, M., Clinton, A., \& Piotrowski, J. (2014). Agentic and communal narcissism and subjective well-being: are narcissistic individuals unhappy? Current Issues in Personality Psychology, 2, 10-16. https://doi.org/10.5114/cipp.2014.43097 